\title{
Web Service Framework for Automating Academic Clearance Processing System
}

\author{
Omogbhemhe Izah Mike \\ Department of Computer Science \\ Ambrose Alli University, Ekpoma
}

\begin{abstract}
Clearance, as it applies to the education sector, is a process whereby the sector verify the authenticity of information provided by the student either at the point of entering the university or at the point of graduation. This kind of system is a student information management system whose main task is to process and manage student clearance data. This clearance exercises subject students to move from one office to another using a particular form (clearance form) in verifying their information by signing this form by officers assigned to these offices. Clearance processing in Nigeria tertiary institutions is unnecessary delayed due to high human involvement in the process. These has resulted in many students fainted during the exercise, some students missed their lectures, test and some students' academic information (result computation) being delayed. This paper argues that the most excellent way for this automation is the establishment of service oriented web system. Consequently, this paper proposed and designed a web service framework suitable for implementing automated clearance processing system in Nigerian tertiary institutions
\end{abstract}

\section{Keywords}

Clearance, Framework, Web Service, Architecture, Nigerian Tertiary Institutions, Academic

\section{INTRODUCTION}

Student clearance document in the education sector, is a copy of authenticated student information that contain all the details of a particular student showing that such student has been verified by the university management. It is a document that has different sections that must be signed by different offices to ascertain if a particular student is free to be accepted by other sections of the university management like examination, result computations, test etc. It is a measures that is actually used by the university management to making sure that student pays all their fees because without it student may not be allowed to write their examination. It can be seen as a proof of graduation in most tertiary institutions in Nigeria, because without it the department will never process the student's final results. In light of the importance of this document, it is therefore vital to the student and the university management. Meanwhile, most Nigerian tertiary institutions process their clearance manually with full involvement of human efforts. Thus, this existing method of processing clearance in Nigerian tertiary institutions is associated with problem as explained below

Stress: Stress is a common occurrence during student's clearance exercise. This factor affects both the students and the officers involve. The existing method is such that the students must be physically present during their clearance and sometime, the large number of student involved in this exercise makes the exercise to be hectic, back-breaking, cumbersome and rigorous for both the officers and the students. Some students always felt sick during and after this exercise and sometime find it difficult to attend lectures or even write exams.

Poor Efficiency: It is a norm in Nigerian tertiary institutions that clearance exercise always takes weeks or even months. This is due to the high level of human involvement in the exercise. Most times the officers to carry out these exercise might be involving in other pressing job, this will end up delaying the clearance exercise for the students.

Insecurity: We have noticed that sometimes because of the large work available for clearance officers, the students have to submit their clearance for to be sign at the convenience of the officer since the task involve verification. In most cases, some student may not find these forms again mainly when large number of forms are being submitted for signing. This makes the current system to be highly unsecured.

Poor Accuracy: When there is a high human involvement in an exercise, errors are inevitable causing clearance to be incomplete and inaccurate. Then, this can render the entire exercise to be full of stress.

In the light of the above, Nigerian tertiary institutions needs a clearance processing system that is stress free, secured, accurate, convenient, and efficient. Meanwhile the huge involvement in the exercise of processing student's clearance in Nigerian tertiary institutions is the root cause of the associated problems. Meanwhile, since automation can eliminate the amount of human involvement in any process to the highest possible level, automating student's clearance exercise in Nigeria tertiary institutions is a sure way to having a better clearance processing system.

For any automated clearance system to be reliable, acceptable and relevant, there is need for such to be in strong alignment with the existing method of carrying out this exercise in many Nigerian tertiary institutions. However, this exercise varies from one institution to another but their sections of clearance and goals are always the same. Hence, the following shows the traditional steps of carrying out this exercise in most Nigerian tertiary institutions.

1. The student obtains the clearance form from the university management through the student's affairs unit or college or registry unit.

2. The student writes his name, matriculation number, department, level and college on the form.

3. The student submits it to the department for verification and signing.

4. Submit it to laboratories (if applicable to a student) for verification and signing

5. Take it to the college for signing and verification

6. Take it to Library for verification and signing

7. Take it to Bursary for verification and signing

8. Take it to audit for verification and signing 
9. Submit it to the verification unit that will perform the general auditing on student credentials.

10. The end of the exercise in some university is to submit the form to the registrar for final signing.

At the end of the above steps the student collect the form and make copies for his/her files. Meanwhile at any point where the student is not cleared, the following unit will not clear such student until the student is cleared by the previous unit. In the light of the above steps, there is no doubt that this method is cumbersome particularly when the university have many students for this clearance exercise. The stress is both experience at the student's end and at the officer's or university management end. Thus, there is need for a better system that can automate this process.

Automating this process is needed considering the steps involves in using the existing clearance system in Nigeria tertiary institutions and considering the everyday increase in the number of students in each university. Hence, this paper proposed a web service framework to realize an automated clearance processing system that is easy to use which can also remove the bottlenecks of the existing system used in processing clearance in Nigerian tertiary institutions.

\section{RELATED WORK}

According to [1], a student information management system is a software application for educational establishment to manage student data. Student information system provides capabilities for entering student test and other assessment scores, building student schedule, tracking student attendance, and managing many other student - related data needs in a school, college or university. [2] explained that student information management system (SIMS) is an integrated software package and it is a data warehouse of student and course information. A complete web based application for all kind of education institution, which is completely web enabled \& operates through internet or LAN. [3] defined 'student information' as data concerning student in an information system. According to [4], a student information system is based on an entity (student information) with data that defines that entity (data attributes), the relationship and coordination of the functions, activities and procedures of the entity and data attributes in a system for purpose of making a decision. [5] stated student information management (SIMS) is a student-level data collection system that allows the department of collect and analyze more accurate and comprehensive information, to meet federal and state reporting requirement, and to inform policy programmatic decision. Student information management system provides the complete information and management for the students, parents, faculties and other staffs of the institution. Managing student information (mainly clearance information) is very important to every higher institutions of learning for accurate and effective decision making. Hence, [6] emphasized that information about students is vital, but time consuming to manage and it is essential that the most effective tools be used to aid both staff and students go about their daily work and studies. Richard emphasized that such management should be given paramount consideration if efficient decision is needed in tertiary institutions. According to [7], the emergence of a computerized based information system has changed the world a great deal, both large and small systems have adopted the new methodology by use of personal computer to fulfil several roles in the production of information therefore computerizing the documentation of student's record/data to enable easier manipulation of the input process and output will bring us to this existing new world of information. According to [8], in examining the document system that is in existence at the school/university that is mostly manual, much importance has been placed on creating a system that documents the students' records using a computerized database system with a secure procedure for accessing it. In the past information systems were manually operated. It usually involves high clerical costs, delay in production of required information, reduction in work throughput, and many at times grave errors and or omissions occur. To overcome these shortcomings, the use of information technology is now employed. But many institutions still have not put the potentials of information technology to work as observed. For instance, many institutions use different forms of spreadsheet applications to collate and process academic results. The deficiencies with this approach include: it does not offer the benefits of a database management system; It does not provide timely information and therefore cannot be relied upon to aid decision making; the availability of results and other information are not real-time [9]. Student's records are very critical and important to the university to establish a more detailed and well organized information or record. [10] develop such student information system but was purely for course management not processing clearance. [11] stated that student information system should provide the needed information about any student to the management, this should include clearance information.

\section{PROPOSED FRAMEWORK}

In computing the acceptable approach to achieving tangible business benefit through technology is identifying the task to be automated, defining the requirement and building the corresponding solution logic of such system. Hence, the most excellent approach to the design of automated systems is the use of service orientation [3]. This is so because, the automated system capabilities are tied to the requirement and processes of the system using the traditional system as a watch manual, thus, there is higher gain of further values, convenient, reliability and conform from using this kind of automated system. Using service orientation approach in designing a framework has shown some useful lessons. Some of these lessons are:

Use of recent technology: Organizations usually have the advantages of recent technology and advancement if any system is to be built from the scratch. Since, IT changes every day, building a system yesterday is deferent from building a system today because of the changes in technology.

Building efficient solutions: Since the solutions requirements are well understood in using this approach, efficient solution can be easily built.

The design solution is always focused: It is always advisable to automate differently all modules of every system processes before the realization of the entire system automation. This makes such automation to be highly focused in designing solutions.

Defining automated process is direct: In using this orientation, designers are focused on the particular process to be automated. They group these process as entities that has methods and properties. This make it easy to implement during the implementation of such design. Meanwhile, service orientation combined successful design element of past approaches with new design elements. In [11] the advantages of service orientation were summarized as follow:

- Increased awareness of available solution 
- Increased behavioural predictability

- Increased scalability

- Functionality and data representation consistency

- Reduced dependencies between solution logic modules

- Using piece of solution logic for multipurpose task.

Meanwhile, a typical web service model consists of the client or front end, middleware and back end or database server. Thus, the proposed framework is based on client/server architecture. In this architecture the system is composed of:

Front end (Client): This is the interface with which the user interacts with on the application. This interface is used by the user to make request to the system server. This interface has the working technology to interact with the system server of the web clearance system. This part of the application can be implemented using ASP.NET.

Middleware (server): This serve as the gateway through which the application interface communicates with the database. All Web transactions take place on the middle end (servers). The web server is responsible for communicating with the browser while the database server is responsible for storing the required information. The web server takes all requests from the clients, responds to the requests and serves the appropriate web pages back to the clients. The primary function of web server is to deliver web pages and associated content to client through Internet Information service (IIS).

The back end: This is the database server that contains the application data. A database server is the storehouse that provides database services to other client on request. Some database management system (like SQL SERVER) relies exclusively on the client server model for database access. Such a server is accessed either through a front-end running on the user's computer which display requested data or the back end which run on the server and handle task such as data analysis, data collation and data storage.

In view of the afore-discussions, this paper proposed a web service framework that can help software developers to building an automated student clearance system that is efficient, convenient and reliable. The framework is as presented in figure 1 .

\section{DISCUSION}

In this paper, we obtained a comprehensive web service framework (model) that is suitable for automating academic clearance system in Nigeria tertiary institutions. If fully implemented, the system will have different modules, graphical user interface module, student data form, student report generation form, security module and database module respectively. The graphical user interface module is used to access the system database, the student data form is used to present different data information of the student for a particular aspect (e.g, Bursary information, Audit information, library information etc), the report generation form is used to generate the end report by each office the student form visited, for the other office to ascertain what is next about the student, the security module is to guarantee maximum security of the system, their forms and the database is to store the student's data and the different report(form) generated by each office concerning a particular student for future reference.

Figure 1 shows the web service framework. The components of this framework are; Department module, Faculty module, Audit module, Laboratories module, Student affairs module, Bursary module, Verification module and Registrar module. Each of these modules interacts with different offices for the clearance of a particular student. After each of the offices has performed its task (clearance) on a particular student form, it saves the end report and process the form to another office for further processes. When a particular office receives a form, such can then access the report generated about the student in the previous office, to check if such student clearance is successful or not, in order to take the necessary action on the student form. This exercise continues till the form get to the registrar modules, which perform the final clearance, generate the report, save the report and send the form back to the student department module, where each department and the student can access the form. Similarly, through the report generation module in the framework, the student can always access/monitor the progress of the form at each office. 


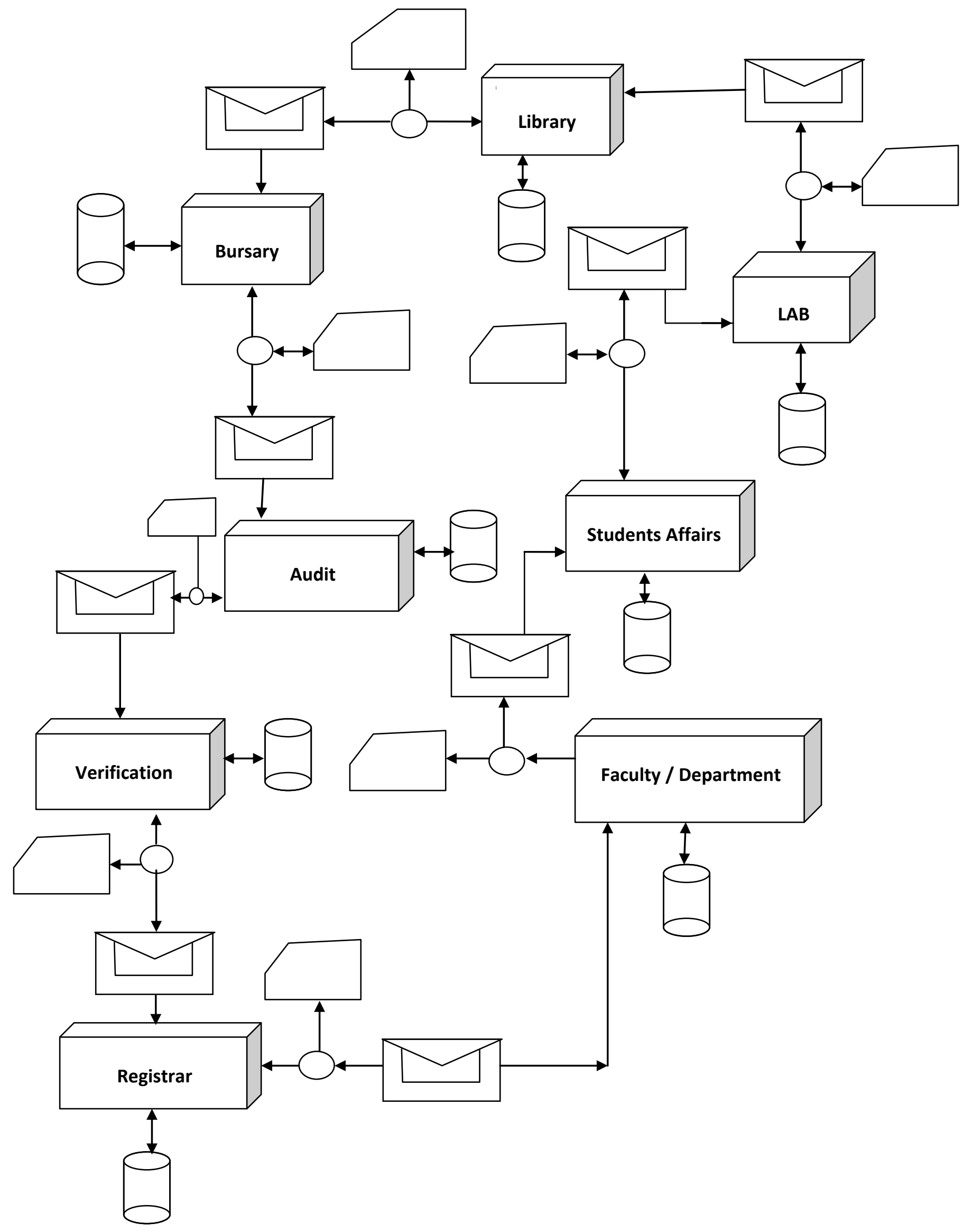

Figure 1: Web Service Framework 


\section{CONCLUSION}

Deploying an automated student clearance system in Nigerian tertiary institutions has a lot of advantages. It will help to improve the efficiency of carrying out student clearance exercise in these institutions. It will remove the stress and bottleneck face when carrying out student's clearance exercise manually. Hence, this paper has presented a web service framework and an easy to understand road map for software developers, suitable for implementing automated student clearance system. If this framework is implemented, we will have a system that will enable students to carry out their clearance exercise at the comfort of their home without having facial contact to any staff that performs the exercise. This kind of system will thereby, help to encourage paperless administration in our university system.

\section{REFERENCES}

[1] Lucky, T. (2006): Management Information System; $12^{\text {th }}$ Edition; DP Publication; London.

[2] Stair R.M. and Reynolds G. (2007): Principles of Information Systems: A Managerial Approach Delmar Learning, Marvel Printery, Toronto,

[3] Lopez G. (2003): “Technological Capabilities Indicators of the State University, new organizational tools for its management guiding and strengthening, and knowledge building and transfer", Proc. IEEE Engineering Management Conference.

[4] Soergel, D. (2005): Organization Information, Principle of
Database \& Retrieval System (Library \& Information Science Series): Academic Technology for Management: Transforming Organization in the Digital Economy $\left(6^{\text {th }}\right.$ edition). Wiley Amsterdam.

[5] Boddy X.D. et al. (2004): Managing Information Systems: An Organizational perspective $\left(2^{\text {nd }}\right.$ Edition). Prentice Hall, U.S.A.

[6] Richard L (2005). Handling Qualitative Data: A Practical Guide. London: SAGE

[7] Jantz R (2001). Knowledge Management in Academic Libraries: Special tools and processesto Support Information Professionals. Referennce Services review 29 1: 33-39

[8] Rainer R.K and Casey G (2012). Introduction to Information System Support and transformation businesses. New Jersey: John Wiley and Sons. Inc.

[9] Botev C. (2005): "Supporting Workflow in a Course Management Sysyem", Proc. ACM Technical Symposium on Computer Science Education (SIGCSE), SIGCSE’05, St. Louis, Missouri, USA.

[10] Moule P. (2006): "Developing the Communities of Practice, Framework for E-learning", Vol. 4, Issue 2, Electronic Journal of E-Learning.

[11] Erl, T.(2008): Principles of Service Design. Prentice Hall, USA. 